\title{
ACONTECIMENTO DISCURSIVO EM MAFALDA: ECOS DA MEMÓRIA DO CICLO DE -AZOS
}

\section{[Discursive Event in Mafalda: Memory Echoes of the azos-Cycle]}

\author{
Luciane Botelho Martins ${ }^{1}$
}

Resumo: À luz da Análise de Discurso de filiação francesa, este artigo propõe reflexões sobre o papel da "memória" no "acontecimento discursivo" marcado no modo de dizer da protagonista de tirinhas argentinas - Mafalda. Assim, a partir da concepção de acontecimento discursivo como o "encontro de uma atualidade e uma memória" (PÊCHEUX, 2008, 17), empreendemos nosso gesto de leitura dividindo a pesquisa em três momentos: no primeiro descrevemos o acontecimento histórico Cordobazo, no segundo discutimos sobre a memória discursiva e o discurso fundador e no terceiro apresentamos nosso gesto de leitura a partir do corpus, formado pela tirinha publicada originalmente na edição da revista em que o acontecimento histórico é noticiado. Ao concluir a análise, observamos que o discurso político-irônico de Mafalda contribui na estabilização de sentidos produzidos pelo acontecimento discursivo na medida em que a memória une o processo linguístico (marcado no sufixo -azo) ao acontecimento histórico.

Palavras-chave: Memória; Acontecimento Discursivo; Discurso Fundador; Mafalda.

Abstract: In the light of the French Discourse Analysis, this article proposes reflections about the role of "memory in "discursive event" which is set in the saying way of the protagonist of Argentinean comic strips - Mafalda. Thus, from the conception of a discursive event as the "encontro de uma atualidade e uma memória" (PÊCHEUX, 2008, 17), we have undertaken our gesture of reading dividing the research into three moments: in the first one, we describe the historical event Cordobazo. In the second part, we discuss about memory and also about the founding discourse, and in the third, we present our gesture of reading considering the corpus formed by the comic strip originally published in the same magazine's edition where is reported the historical event. In concluding the analysis, we observe that Mafalda's political-ironic discourse contributes to the stabilization of the senses produced by the discursive event as memory unites the linguistic process (set in the suffix -azo) with the historical event.

Keywords: Memory; Discursive Event; Founding Discourse; Mafalda.

1 Doutora em Letras pela UFPel (2020), professora da Prefeitura Municipal de Rio Grande, RS. E-mail: lucianebmk@ hotmail.com. 


\section{INTRODUÇÃO}

Primeiramente, é preciso antecipar que o trabalho que estamos apresentando constitui um dos recortes da tese "Memória e resistência: um estudo sobre o pré-construído e o discurso transverso através da ironia em Mafalda", pesquisa que visou compreender os processos discursivos em funcionamento na ironia, considerando o papel da memória e da história em dois funcionamentos do interdiscurso: o pré-construído e o discurso transverso. Neste recorte, nosso objetivo é mostrar o funcionamento da "memória" no "acontecimento discursivo" linguisticamente marcado pelo sufixo -azo no texto híbrido2 - tirinha de Mafalda, uma produção argentina que no âmbito da circulação vem rompendo fronteiras geográficas e linguísticas (Mafalda possui 27 traduções, incluindo a Língua Guarani). Diante disso, tendo como escopo teórico metodológico a análise de discurso de filiação francesa, buscamos com esta pesquisa contribuir com os estudos de leitura/interpretação do gênero híbrido - tirinha. Para dar conta do objetivo proposto neste artigo, delineamos o trabalho da seguinte forma: num primeiro momento, apresentaremos o fato que constituiu o acontecimento histórico na Argentina - o Cordobazo - noticiado no mesmo suporte midiático em que Mafalda originalmente também circulou - Revista Siete Dias Ilustrados; em seguida, retomaremos os conceitos que envolvem o funcionamento da memória discursiva (pré-construído e discurso transverso) na acepção de Pêcheux (2009), o discurso fundador, conforme aponta Orlandi (1993) e o acontecimento discursivo, segundo Pêcheux (2008). Elencados os conceitos, passaremos ao processo de leitura da tirinha que apontará que a memória resiste no discurso político irônico, uma vez que se materializa como acontecimento discursivo por meio dos sentidos produzidos pela sincronia entre as linguagens verbal e não verbal.

\section{ACONTECIMENTO HISTÓRICO COMO PONTO DE PARTIDA}

Em 1969, a Argentina vivia sob o comando de um governo autoritário, cujo chefe maior era o presidente golpista3 - General Onganía. Assim, dado o descontentamento de trabalhadores e estudantes, em dia 29 de maio de 1969 deu-se em Córdoba4 aquele que viria a ser o primeiro e mais violento confronto dentre tantos que marcariam a história de luta do país contra regimes autoritários. Na época, a CGT (Confederação Geral do Trabalho) havia organizado uma mobilização junto aos trabalhadores das fábricas automotivas que culminaria em uma greve geral com data prevista para 30 de maio. No entanto, de forma

2 Entende-se por texto híbrido aquele cujo sentido é construído a partir do trabalho conjunto entre duas linguagens: a verbal e a não verbal.

3 O General Onganía destituiu o Presidente eleito democraticamente - Arturo Illia - e assumiu o poder com o apoio das Forças Armadas e da mídia impressa em 1966, permanecendo no poder até 1970.

4 Córdoba é a capital da província argentina que recebe o mesmo nome. A cidade de Córdoba está separada da capital federal Buenos Aires por aproximadamente $695 \mathrm{Km}$. 
desarticulada com outras lideranças da CGT, o vandorista5 Elpidio Torres (também líder sindical) propôs que a parada começasse quatorze horas antes. Diante dessa orientação, cerca de cinco mil trabalhadores e estudantes atendendo ao chamado saíram pelas ruas de Córdoba em um protesto que durou 48 horas. Em entrevista ao La Izquierda Diario6, o historiador Leonidas Ceruti explicou que,

El movimiento obrero industrial se hizo cargo de ese liderazgo social y arrastró al pueblo todo a la lucha antidictatorial. Se retomó la vieja tradición, que cuando fueron agredidos los trabajadores en todo el mundo han respondido tomando en sus propias manos, y organizando su defensa (CERUTI, 2017).

Como podemos observar através das palavras do historiador, o objetivo do movimento era lutar contra a ditadura instaurada pelo General Onganía, bem como, contra sua política de governo. Nesse ponto, convém ressaltar a importância desse movimento, porque foi ele que deu início a uma série de outros movimentos conhecidos por compor o ciclo de "azos". Esses movimentos tinham em comum um mesmo objetivo: combater os governos autoritários. Nesse cenário, é relevante destacar que diferentes partidos políticos se uniram, de radicais a nacionalistas e, claro a esquerda de raiz marxista, a qual agregava à luta comum de enfrentamento aos governos autoritários o desejo de formar uma revolução de liberação social e nacional, em prol de uma sociedade socialista na Argentina.

Diante disso, o que chamou a atenção e motivou esta pesquisa foi o fato de a revista Siete Dias Ilustrados ${ }^{7}$ não ter publicado nenhuma explicação sobre as motivações que geraram o confronto que ficou conhecido como Cordobazo, pelo contrário, as imagens impactantes mostravam a destruição nas ruas da cidade de Córdoba, bem como as imagens do grupo de trabalhadores que foi detido pela polícia, entre eles o líder do movimento Elpidio Torres - que rapidamente foi condenado pelo tribunal militar a cumprir uma pena de quatro anos e oito meses pelo "crime" de incitação à rebelião, nos termos publicados na revista. Frente ao exposto, observamos que a posição assumida pela revista é clara: ela está funcionando como porta-voz do governo e não em defesa dos direitos dos trabalhadores e dos estudantes. A posição assumida pela revista é tão identificada com o governo que ela dedica uma página inteira com a cobertura e trechos do pronunciamento de Onganía sobre o conflito. O texto apresentado com o título "Los ecos del Cordobazo" explica que em virtude do acontecimento em Córdoba, o presidente precisou valer-se dos meios de comunicação

5 O termo "vandorista" era a denominação utilizada por aqueles que seguiam a orientação de Augusto Timoteo Vandor, um líder sindical que se opôs a Juan Domingo Perón assim que o presidente foi destituído do cargo em 1955. Vandor, na época, foi responsável pela divisão interna na CGT (formada pelos "vandoristas", que não tinham espaço para agir e pelos "participacionistas" que acatavam as decisões impostas pelo governo, sem reagir).

6 A entrevista concedida ao Jornal on-line La Izquierda Diario pelo historiador Leonidas Ceruti, está disponível para consulta em <http://www.laizquierdadiario.com/Que-fue-el-Cordobazo-y-cuales-fueron-sus-consecuencias>

7 A revista Siete Dias Ilustrados foi uma revista de grande circulação na Argentina, sobretudo pelo seu diferencial que era a cobertura de acontecimentos por meio de fotojornalismo. Foi nesta revista que as tirinhas de Mafalda circularam no período compreendido entre de julho de 1968 a junho de 1973, momento em que Quino, decide parar a produção inédita das tirinhas de Mafalda. 
- rádio e TV - em 4 de junho, para informar a população sobre algumas mudanças, entre elas: a renúncia de todo o seu gabinete; a troca do comando das pessoas que o assessoravam (a pedido das Forças Armadas); e, a aprovação de uma nova lei (mais severa) contra comunistas. É possível notar que em vários trechos da matéria, a revista transcreve fragmentos da fala de Onganía, entre os quais destacamos:

"No todo lo hecho en estos últimos años está bien hecho", [...] "pero habría que rastrear mucho en la historia para encontrar otros tres años tan llenos de realizaciones";

"No habrá retroceso ni debilidades, no habrá flaquezas";

"Las Fuerzas Armadas se encuentran, hoy más que nunca, unidas al servicio de los objetivos señalados el 28 de junio de 1966” (ONGANÍA, 1969, p. 13).

As transcrições revelam o discurso de um presidente golpista reafirmando o seu poder pela força militar como justificativa para a manutenção da ordem e de uma Revolução Argentina - motivos que o levaram a intervir e impedir que o mandato do presidente legitimamente eleito pelo povo - Illia - fosse concluído a seu tempo. Dito de outro modo, Onganía não demonstra qualquer declinação ao diálogo com os manifestantes, revelandose ainda mais prepotente e autoritário do que antes. E, é em meio a esses acontecimentos históricos que a tirinha de Mafalda, objeto deste estudo, foi produzida e é identificada aqui como sequência discursiva de referência para que a partir dela possamos desenvolver nossa pesquisa sobre o funcionamento da memória e do acontecimento discursivo.

\section{MEMÓRIA E ACONTECIMENTO DISCURSIVO: DOIS CONCEITOS DA AD}

Para Pêcheux "nenhuma memória pode ser um frasco sem exterior" (2010, p. 56), isso significa dizer que a memória não se limita a saberes fixos e absolutos, pelo contrário, a memória é lugar de saberes que sofrem reformulações, dissensões e apagamentos. A partir da compreensão da memória como sítio dos sentidos em movimento é que Pêcheux (2009) problematiza os dois funcionamentos da memória: o pré-construído (como conjunto de dizeres já-ditos e esquecidos que emergem no intradiscurso) e o discurso transverso (como um modo dizer implícito, cujo sentido traz sustentação ao dito), revelando as posições no discurso. Isso implica dizer que as palavras adquirem sentidos na relação que estabelecem com as formações ideológicas inscritas pelas posições ocupadas pelo sujeito que as enuncia. Contudo, é de suma importância destacar que, assim como a memória, as Formações Discursivas - FDs não são lugares absolutos e os efeitos de sentidos não possuem natureza fixa e homogênea, estando, portanto, sujeitos a rupturas pontuais, conforme aponta Orlandi (1993).

Essas rupturas pontuais são responsáveis pelo que Orlandi (1993) conceituou como discurso fundador, isto é, a autora definiu como discurso fundador um "marco" que instala 
condições para a formação de "novos" discursos, "filiando-se à sua própria possibilidade, instituindo em seu conjunto um complexo de formações discursivas, uma região de sentidos, um sítio de significância que configura um processo de identificação" (p. 24) para um determinado grupo social. Entretanto, é necessário lembrar que não podemos confundir o discurso fundador com a origem do dizer, pois os dizeres constituem um conjunto de já-ditos, os quais ocupam lugares relativos, não fixos das Formações Discursivas, conforme definiu Pêcheux (2009).

Orlandi, ao tratar desses "lugares" reafirma que "essa questão do 'lugar' fica assim re-significada a partir do fato de que há uma história de constituição dos sentidos, ou seja, eles não são considerados em sua 'essência'" (1993, p. 7), até porque a ideia de um sentido fixo é inadmissível na teoria discursiva com a qual estamos trabalhando. Assim, a autora esclarece que a relação dos sentidos com o lugar ocupado "não é nem direta, nem automática, nem de causa e efeito, e nem se dá termo-a-termo" (ORLANDI, 1995, p. 113), mas se constitui a partir de uma "necessidade do sentido no universo simbólico". A autora se refere à historicidade, outro conceito caro à Análise de Discurso e cujo trabalho está no jogo entre a história do sujeito e a história do sentido, pois não há sentido sem história (a história provê a linguagem de sentidos). Resulta daí que historicidade não é sinônimo de história, pois a história é fixa, absoluta e dada. A historicidade diz respeito a um processo de constituição de sentido que, ao longo do tempo, pode estabilizá-lo, mas jamais fixá-lo, visto que a partir de seu caráter não-absoluto, qualquer sentido está sujeito a deslizamentos e deslocamentos passando a constituir um sentido-outro. Nesse ponto, a autora ressalta que "a organização dos sentidos é trabalho do ideológico" (1993a, p. 7), daí a possibilidade de ruptura no/do sentido, visto que conforme aponta Pêcheux (2009) "Não há ritual sem falhas", ou seja, o discurso como fundador, "cria uma nova tradição, ele re-significa o que veio antes e institui aí uma memória outra” (ORLANDI, 1993b, p. 13).

Assim, é importante lembrar que quando pensamos em memória discursiva estamos pensando a memória como efeito, como sítio onde a materialidade discursiva é estruturada, um lugar de repetição e regularização de dizeres. Nos termos de Pêcheux (2010), pensar a memória discursiva é pensar a "condição do legível em relação ao próprio legível" (2010, p. $52)$.

Com vistas nisso é que Orlandi (1993b) designou como "filiação", ou seja, como discurso fundador o fenômeno em que o "novo" instala-se e produz o efeito de permanente, momento em que o "já-dado" intervém no "novo" produzindo um sentido-outro. Conforme aponta Orlandi (1993b), o discurso fundador é capaz, em si, de muitos sentidos entre os quais estão aqueles que dão origem a uma nova ordem do discurso.

É importante destacar que ao tratar das filiações históricas em memórias, Pêcheux explica que essa organização juntamente com as "relações sociais em redes de significantes" (2008, p. 54) é o que possibilita a ligação, identificação e transferência entre o outro da história e o outro da linguagem. Segundo o autor, ao tratarmos sobre a relação desses dois outros, não estamos tratando "de duas fases sucessivas, mas de uma alternância ou de um batimento" (2008, p. 54). Nos termos do autor, 
...todo discurso marca a possibilidade de uma desestruturação-reestruturação dessas redes e trajetos: todo discurso é índice potencial de uma agitação nas filiações sócio-históricas de identificação, na medida em que ele constitui ao mesmo tempo um efeito dessas filiações e um trabalho [...] de deslocamento no seu espaço (PÊCHEUX, 2008, p. 56).

Em outras palavras, quando de modo contingente, o fato linguístico do equívoco opera na ordem do simbólico (estrutura) e, nessa operação, há "pega" 8 , segundo a terminologia apresentada por Althusser (1982), surge o acontecimento. Daí a afirmação de Pêcheux de que o acontecimento discursivo define-se pelo "encontro de uma atualidade e uma memória" $(2008,17)$.

Já no que concerne a memória e seu funcionamento através da repetibilidade, Pêcheux justifica que o processo não é fechado porque a memória não é uma esfera plena, cujo conteúdo é homogêneo, ela é sim, "espaço móvel de divisões, de disjunções, de deslocamentos e de retomadas, de conflitos, de regularização... um espaço de desdobramentos, réplicas, polêmicas e contra-discursos" (2010, p.56). Daí a possibilidade de movimento dos sentidos problematizada por Indursky. A autora destaca que a repetição "pode levar a um deslizamento, a uma ressignificação, a uma quebra do regime de regularização", e isso decorre do fato de que "o sujeito do discurso pode contraidentificar-se com algum sentido regularizado ou até mesmo desidentificar-se de algum saber e identificar-se com outro" (2011, p. 71). E, é com base nisso, que a Análise de Discurso está pensando a resistência, isto é, como sentido que irrompe revelando o que de alguma forma está ali, permanecendo, pois, conforme apontam Ernst-Pereira e Quevedo, ao descrever o funcionamento do discurso transverso no texto híbrido (charge de Latuff), embora o "dizer esteja aparentemente fora do que é dito (embora seja um não-dito que significa pelo efeito de sua presença-ausência), é no que é dito que esse dizer é atualizado como echapéé, que funciona à revelia do sujeito que o avaliza" (2013, p. 338). A partir disso, nossa leitura desdobra-se sobre a materialidade - tirinha de Mafalda, um texto híbrido, cujo discurso assume o caráter irônico para dizer aquilo que não pode, não deve ser dito, mas que via memória resiste como eco de um acontecimento discursivo.

\section{MAFALDA COMO MATERIALIDADE DE UMA MEMÓRIA QUE RESISTE}

A tirinha que constitui a sequência discursiva que analisamos neste trabalho foi publicada poucos dias depois do conflito Cordobazo, na mesma edição da revista Siete Dias

8 Segundo Althusser, a estabilidade de um sentido/saber vem da consumação e reconhecimento de fatos dados pela fixação - "pega" - de um encontro entre processos sem sujeito. Nos termos do autor, "...uma vez consumado o fato, se instaura o reino da Razão, do Sentido, da Necessidade e da Finalidade. Mas esta consumação do fato é somente um puro efeito da contingência, dado que depende do encontro aleatório dos átomos como consequência do desvio, do clinamen" (1982, p. 11). Melhor dizendo, a consumação de um fato resulta de um encontro que é da ordem do contingente, daí a denominação de desvio. Segundo o autor, "qualquer coisa não pode produzir qualquer coisa, mas só os elementos destinados, graças à sua afinidade, a encontrar-se e a "pegar" uns sobre os outros" (1982, p. 27-28) é que pode constituir uma forma, uma estrutura. 
Ilustrados que trata sobre o acontecimento histórico conforme descrevemos na primeira parte deste artigo. É importante destacar que o Cordobazo está sendo tomado não só como um acontecimento histórico, mas também e principalmente como um acontecimento discursivo. Tal afirmação encontra sustentação na teoria materialista porque no que concerne o campo do discurso é importante atentar ao fato de que o termo "Cordobazo", cujo recurso à morfologia possibilita a formação do novo vocábulo a partir da anexação do sufixo "azo" ao nome próprio "Córdoba", passa a constituir-se como acontecimento discursivo, na medida em que esse processo linguístico encontra-se afetado pelo acontecimento histórico da sublevação e resistência e pela produção de uma agitação das filiações sócio-históricas de identificação (cf. Pêcheux, 2008), sobretudo porque esse processo de identificação passa a designar outros movimentos de resistência na Argentina com características similares. Em outras palavras, o acontecimento marcado linguisticamente pelo acréscimo do sufixo formador originariamente de aumentativo em espanhol ao substantivo próprio de natureza topográfica e, consequentemente, pelo efeito de sentido daí resultante, ligado à luta e à resistência dos oprimidos frente à dominação atua nas redes de memória e passa a designar outros eventos por um processo de ressignificação, entre os quais estão o Rosariazo e o Viborazo, por exemplo.

Diante disso, passemos ao processo de análise, atentando para cada elemento (formulação verbal e visual) que compõe a sequência discursiva materializada na figura a seguir.

Figura 1: Crescimento truculento
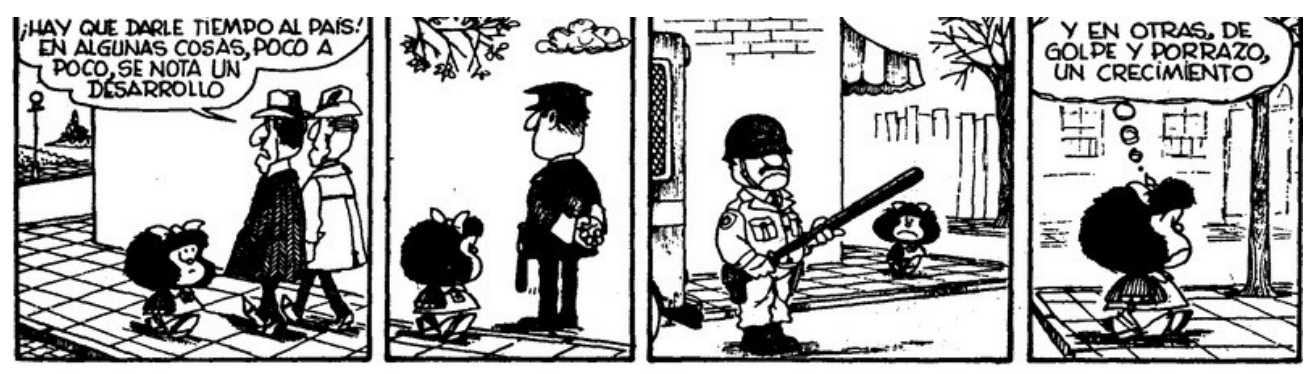

Fonte: QUINO. Siete Dias 08 a 14-06-1969, Año 3, No 109, p.32.

A tirinha formada por quatro quadros assimétricos já aponta na forma de apresentação uma ruptura com o que é esperado enquanto estrutura tirinha. Isso encontra sustentação em Martignone \& Prunes (2010), sobretudo quando os autores comparam Mafalda a outras produções locais. Os autores destacam que Mafalda revolucionou o mundo dos quadrinhos argentinos porque rompeu com a modelo tradicional da época, que repetia uma estrutura de quadros simétricos, com uma única protagonista, cuja característica era "la caricatura

9 Gramaticalmente, os nomes próprios identificam um referente único com identidade distinta dos demais referentes e também não trazem uma descrição de seus referentes como os substantivos comuns. (cf. NEVES, 2000) Portanto, os nomes próprios topográficos aí se enquadram, na medida em que denominam um determinado lugar e não o descrevem. Entretanto, seu emprego junto com o sufixo "azo", dadas as condições histórias de emprego, tomam uma configuração particular, não apenas de identificação de um lugar específico, mas de luta antiditatorial organizada pelos sindicatos de Córdoba com o apoio de estudantes universitários, de partidos políticos e do povo. 
descarnada de un estereotipo porteño incorrigible e inmodificable" (p. 34), ou seja, o modelo tradicional refletia em um humor previsível, enquanto em Mafalda, segundo os autores,

Quino optó por presenta una galería de personajes más variada y compleja, donde cada personaje representara una o varias ideas o tipos. El mecanismo, o la gracia de la tira, aquí ya no consiste en la burla-celebración del estereotipo, sino en los conflictos que surgen a causa de las diferentes filosofías de vida de los protagonistas, de sus diferentes actitudes hacia el mundo y las personas que los rodean y con los cuales tienen que ingeniar selas para convivir (MARTIGNONE \& PRUNES, 2010, p. 34)

Através de Mafalda, Quino apresenta uma nova forma de "fazer tirinha", pois suas personagens refletem as diferentes formas de pensar os conflitos, as angústias e as inquietudes da sociedade. Decorre daí uma abordagem distinta das personagens, as quais são tomadas tanto sob o ponto de vista psicológico quanto sob o ponto de vista social, refletindo, dessa forma a realidade argentina, mesmo que essa realidade corresponda a de uma parcela dessa sociedade - aquela que se autodeclarava como classe média. Martignone \& Prumes acrescentam ainda que Quino,

...al tratar mayormente de temas, costumbres y personajes del propio país, establece una diferencia de base con las tiras norteamericanas y posibilita una mayor identificación por parte del lector nacional al que está dirigida, de esta manera, puede explicarse en parte la enorme repercusión de Mafalda, que tan inteligentemente retrató nuestras costumbres y lenguaje. Aun cuarenta años más tarde, frases, personajes y chistes siguen siendo perfectamente reconocibles dentro de la cultura argentina (2010, p. 77).

Nesse sentido, os autores reforçam que Mafalda representa um marco no processo que renovou a tirinha argentina pelo "novo" instaurado no estilo e caráter estético, na variedade de personagens e nos temas de relevância locais. Isso posto, nos é permitido pensar a tirinha como um gênero discursivo específico que trabalha a produção e a circulação de sentidos, constituindo-os discursivamente não somente pelo que diz, mas pelo modo como diz, valendo-se do entrelaçamento de recursos dos campos verbal e não verbal.

Voltando leitura da tirinha, na primeira cena, temos ao centro, a figura da protagonista que, ao caminhar pelas ruas da cidade portenha, passa por dois homens brancos e bem 
vestidos que refletem a imagem da classe média10 argentina. Notamos que, enquanto os homens conversam, Mafalda apenas os observa atentamente. A imagem da protagonista já aponta de antemão um sentido de preocupação frente ao dizeres dos sujeitos que representam uma parcela da sociedade argentina - a classe média. Quanto ao enunciado produzido por uma das figuras “¡Hay que darle tiempo al país! En algunas cosas, poco a poco, se nota un desarrollo", podemos identificar que há o funcionamento de um discurso transverso (memória), na medida em que se estabelece uma relação de causa e efeito entre tempo despendido e desenvolvimento econômico. Dizeres já ditos antes em outro lugar, portanto, retornam no discurso produzido pelos interlocutores ouvidos por Mafalda. O último enunciado, produzido por Mafalda, é marcado ironicamente pelo discurso do autoritarismo que, para "manter a ordem", utiliza-se da força. Situa-se no eixo parafrástico, remetendo a já-ditos pelo presidente durante seu pronunciamento em rede nacional: "No todo lo hecho en estos últimos años está bien hecho", [...] "pero habría que rastrear mucho en la historia para encontrar otros tres años tan llenos de realizaciones”11 (Onganía apud Siete Dias, 1969, p. 13).

Podemos dizer ainda que, no processo de produção do dizer dos interlocutores observados pela protagonista há um efeito claro do trabalho da ideologia conforme explica Žižek,

... a ideologia não é simplesmente uma "falsa consciência", uma representação ilusória da realidade; antes, é essa mesma realidade que já deve ser concebida como "ideológica": "ideológica" é uma realidade social cuja própria existência implica o não-conhecimento de sua essência por parte de seus participantes, ou seja, a efetividade social cuja própria reprodução implica que os indivíduos "não sabem o que fazem". "Ideológica" não é a "falsa consciência" de um ser (social), mas esse próprio ser, na medida em que ele é sustentado pela "falsa consciência" (1996b, p. 305-306).

A partir disso, podemos afirmar que ambos: o presidente enquanto sujeito e a personagem (homem branco) enquanto efeito-sujeito, são interpelados ideologicamente pelo mesmo saber, trata-se do trabalho da memória funcionando na tirinha como discurso transverso, em que o dito produzido pelo sujeito-presidente retorna no eixo parafrástico do dizer do interlocutor da tira, produzindo um efeito de sentido estável, aquele que reafirma que o governo está no caminho certo e que por isso é preciso paciência por parte da população.

\footnotetext{
10 A partir de Adamovsky (2012), podemos definir a classe média como uma classe forjada, isto é, uma classe que se estabiliza durante o primeiro mandato do governo Perón, quando o então presidente aposta em melhorias nas condições/ relações de trabalho, dividindo o proletariado em classe trabalhadora e classe média. Perón compreendia que o trabalho era o motor do país, sinônimo de desenvolvimento e prosperidade e que, portanto, entendia a necessidade de ter a classe trabalhadora ao seu lado. Por essa razão investiu nela e na "higienização dos costumes" dessa classe, pois seu projeto era a formação de uma identidade nacional argentina. Isso promoveu uma divisão: nativos, negros e imigrantes mestiços de poucas posses formaram a classe operária. Já os imigrantes portadores de algum bem, pequenos proprietários, comerciantes, docentes e profissionais ascenderam e formaram uma outra classe (a classe média). Adamovsky (2012) destaca ainda que o projeto que deu origem a classe média não foi um projeto social, mas um projeto político. Nesse sentido vale registrar que essa classe média, que "ganhou corpo" ao longo do governo de Perón, foi a mesma que fez frente no processo que o levou a renunciar ao segundo mandato, bem como a mesma que "encabeçou" a série de movimentos golpistas que vieram na sequência, instalando governos interventores e extremamente autoritários.
}

$11 \mathrm{O}$ trecho do discurso de Onganía poder ser assim traduzido: "Nem tudo o que foi feito nestes últimos anos está bem feito, [...] no entanto, temos que rastrear muito na história para encontrar outros três anos tão cheios de realizações". 
A passagem para a segunda cena, nos mostra que Mafalda continua caminhando, ela está em movimento enquanto observa a figura de um policial que está parado, de costas e com as mãos postas para trás. O sentido produzido pela imagem do policial é um sentido de vigilância passiva, visto que teoricamente ao policial argentino compete a função de manter e zelar pela segurança da população. No entanto, convém observarmos que o fato de a figura ter sido retratada de costas produz um sentido de passado, ou seja, o clima de paz e tranquilidade é algo que não corresponde mais ao tempo presente da narrativa. Podemos notar, ainda, que a imagem vista em segundo plano, não apresenta um cenário urbano, mas uma espécie de cenário retrô, composto apenas por uma nuvem e um galho com folhas. Nesse sentido, reafirmamos: a cena produz um efeito de sentido que rememora um passado.

É, pois, na passagem do segundo para o terceiro quadro que podemos observar o processo de construção dos sentidos que promove uma ruptura. Principalmente, porque há uma mudança brusca na composição da cena. O terceiro quadro traz, em segundo plano, um cenário urbano, sentido produzido a partir de marcas imagéticas, tais como: construções residenciais, cerca de madeira e árvore sem folhas (sem vida). Chama-nos atenção, a mudança na forma como a árvore aparece nessa cena, pois ela produz um duplo efeito: o de que o tempo passou e o de que tempos difíceis estão por vir (esse sentido apoia-se na própria natureza das estações do ano, em que o outono como estação de transição, é prenúncio de tempos difíceis - o inverno -, ritual que se materializa pelo cair das folhas, já secas e sem vida). Mafalda ao compor esse segundo plano da imagem é graficamente produzida em tamanho menor que o normal, além disso, a protagonista se depara com a figura de um militar bem diferente daquela retratada na cena anterior. Ou seja, Mafalda se vê diante da figura de um militar em posição de combate, sentido produzido pelo gesto de segurar um bastão proporcionalmente maior que o comum e pela indumentária em que o sapato dá lugar às botinas e o cap dá lugar ao capacete (indumentária usada em situação de confronto e/ou de guerra). Podemos observar ainda que, compondo a imagem encontra-se a parte traseira do camburão - um veículo parado - que produz o sentido de que o militar não se encontra só, pelo contrário, ele pode contar com o apoio de outros militares. Notamos que diante dessa cena, a expressão de Mafalda também muda. A expressão inicial de reflexão e preocupação dá lugar a um misto de medo, decepção e tristeza.

Mas entre tantos elementos, o que chama nossa atenção encontra-se no quarto e último quadro em que o sujeito protagonizado por Mafalda produz "um dizer", o qual se materializa sob a forma de pensamento "Y en otras, de golpe y porrazo, un crecimiento" 12. Podemos observar que o dito é contraditório se pensarmos a relação "desenvolvimento" - "crescimento" versus crescimento da violência. Notamos que, é na segunda opção que o efeito de sentido de "crescimento", quando enunciado pelo sujeito protagonizado por Mafalda, reside, já que se trata de um desenvolvimento que se dá às custas do crescimento da violência ou, em outros termos, um desenvolvimento que só é possível mediante um controle autoritário regido por práticas de violência e de opressão, sentido sustentado pela análise do funcionamento da ironia ${ }^{13}$.

12 Traduzido como: "E em outras, um crescimento truculento"

$13 \mathrm{O}$ trabalho completo sobre o funcionamento discursivo da ironia encontra-se descrito na tese de doutorado de Martins (2020), sob o título: "Memória e resistência: um estudo sobre o pré-construído e o discurso transverso através da ironia em Mafalda". 
Mas, voltemos à formulação verbal: "Y em otras, de golpe y porrazo, un crecimiento". Nela, há pelo menos três elementos sobre os quais nossa atenção se volta para desenvolver essa reflexão: golpe, porrazo e crecimiento. Podemos pensar, primeiramente, o termo golpe como um elemento de referência que se faz recuperável pela relação que estabelece com a segunda cena (que contém a imagem do policial que mais parece um civil, dada sua tranquilidade). Se remontarmos a história, veremos que o General Onganía, durante o período que participou da construção das condições junto à mídia impressa para o golpe de 66, também refletia uma imagem de tranquilidade, ou seja, as características agrupadas na figura do policial fazem funcionar por meio da memória a correspondência ao conjunto de características de Onganía antes do golpe. Sua retórica reforçava a urgência na retomada do desenvolvimento e do crescimento da Argentina. No entanto, sabemos que após a tomada de poder, via golpe, até mesmo seus aliados viram-se surpresos com tom autoritário que o golpista deu ao seu governo, pois até a revista criada para o fim específico de construir elementos para o golpe de 66, por meio de discursos que desqualificavam o governo legítimo de Illia e apontavam Onganía como "solução" - Primera Plana - foi fechada assim que o interventor assumiu o poder, deixando perplexa toda a equipe da revista que o havia apoiado incondicionalmente.

Assim, ao observarmos os dois quadros, percebemos uma mudança na forma como o policial é retratado no segundo e na forma como aparece o militar no terceiro (de passivo a agente; de passado a presente), as duas imagens apontam para o processo de militarização da polícia, um processo característico de governos autoritários na Argentina. Transformação que, desse modo, coincide com a que ocorreu com o governo argentino (antes de 66; depois de 66).

Outro elemento extremamente importante e que motivou essa análise é a "coincidência" na escrita do vocábulo porrazo, o qual nos faz, imediatamente recuperar, via memória, o acontecimento discursivo marcado pelo Cordobazo.

Frente ao exposto, somos autorizados a dizer que o discurso irônico, como efeito de dissonância entre sentidos em disputa, toma forma a partir da relação que os elementos da última formulação verbal (golpe e porrazo) estabelecem como já-ditos que retornam no intradiscurso (segunda e terceira cenas da tirinha) sob a forma de pré-construídos, mais especificamente nas figuras do policial e do militar. Dito de outro modo, por meio de uma anáfora discursiva14 o linguístico (golpe - porrazo) retoma no visual (policial - militar) elementos de saber que são da ordem da memória de dizeres - do interdiscurso.

Com base nisso, podemos pensar em duas formações discursivas distintas para a materialidade significante, uma FD do Estado Democrático e outra opressora - a FD do Estado Autoritário, para as quais os termos "desenvolvimento" e "crescimento" são elementos de saber comuns, mas que, uma vez produzidos por formações discursivas diferentes produzem sentidos, também, diferentes.

Frente ao exposto na análise, podemos inferir que a posição-sujeito assumida por Mafalda, na tirinha, enuncia um dizer que produz um sentido de denúncia da violência de

14 De acordo com Indursky, “A anáfora discursiva constrói-se, pois, sobre um dito retomado na superfície textual e sobre um já-dito retomado na exterioridade do texto. [...] é sobre o segundo que se ancora a referência do dizer atual e a coerência discursiva. É ainda em relação a este segundo laço coesivo que o sujeito do discurso toma posição" (1995, p. 07, grifo da autora). 
estado, ou seja, o sujeito vale-se de uma expressão comum às duas FDs (desenvolvimento e crescimento), mas que associada à "golpe" e "porrazo" revelam o lugar onde o sentido é produzido - FD do Estado Autoritário. Ou seja, temos um sentido de resistência construído por meio da ironia, uma vez que o sujeito protagonizado por Mafalda joga com os sentidos de duas ordens de forma simultânea, gerando um efeito de dissonância à medida que atualiza no nível enunciativo um acontecimento discursivo, marcado no duplo sentido de "golpe" e na presença do sufixo - azo no vocábulo "porrazo".

\section{CONSIDERAÇÕES FINAIS}

A análise de discurso, ao surgir na França na década de 60, teve como materialidade para observação de seu funcionamento o discurso político produzido pela linguagem verbal. Aos poucos, a teoria viu-se desafiada a abrir-se para outras materialidades, entre as quais está o texto híbrido tirinha que produz sentido a partir das relações que a sincronia da linguagem verbal com a linguagem não verbal produz ao ser submetido ao processo de leitura pelo sujeito-leitor. E foi diante do desafio de ler discursivamente o texto do gênero tirinha que a tese e, consequentemente este trabalho foi surgindo.

Vimos ao longo do artigo que o acontecimento histórico em Córdoba não só foi marcado linguisticamente pelo acréscimo do sufixo -azo como evento, mas também e sobretudo, foi marcado como movimento de luta e resistência aos governos autoritários, inaugurando uma nova ordem à medida que "funda" uma série de outros eventos. Com base nisso sustenta-se que o Cordobazo funcionou como discurso fundador (Cf. Orlandi, 1993b) no conceito que Pêcheux (2008) denominou como acontecimento discursivo.

A partir disso, é possível observar que o discurso político e irônico de Mafalda revela por meio do funcionamento da memória um discurso de resistência aos regimes golpistas/ autoritários tanto quanto os acontecimentos históricos, ao jogar com os sentidos que o linguístico e o imagético assim imbricados produzem ao serem discursivizados. Dito de outro modo, o jogo simultâneo entre duas ordens, dado por formações discursivas antagônicas entre si (FD Democrática e FD Autoritária) característica constitutiva do discurso político-irônico produzido em Mafalda aponta no modo de dizer dado pelo acréscimo do sufixo -azo em porrazo o papel da memória no processo que faz emergir o acontecimento discursivo e os sentidos de resistência nele historicizados. 


\section{REFERÊNCIAS BIBLIOGRÁFICAS}

ADAMOVSKY, E. Historia de la Clase Media Argentina - apogeo y decadencia de una ilusión, 19192003. $5^{\text {a }}$ ed. Buenos Aires: Grupo Editorial Planeta, 2012.

ALTHUSSER, L. A corrente subterrânea do materialismo do encontro (1982). Disponível em < https:// www.marxists.org/portugues/althusser/1982/mes/corrente.pdf.> Acesso em: 05/11/2017.

ERNST-PEREIRA, A. \& QUEVEDO, M. Pré-construído e discurso transverso: ferramentas de derrisão em uma charge de Latuff. In: Desenredo - Revista do programa de Pós-graduação em Letras da Universidade de Passo Fundo. Volume 9, No 2, pp. 325-339 - jul./dez. 2013. Disponível em: http:// webcache.googleusercontent.com/search?q=cache:i9yVS99cNnc):seer.upf.br/index.php/rd/article/ view/3851+\&cd=1\&hl=pt-BR\&ct=clnk\&gl=br Acesso: 08/01/2020.

INDURSKY, F. Da anáfora textual à anáfora discursiva. Anais do I Encontro do CELSUL. Florianópolis, UFSC, nov. 1995.

INDURSKY, F. A memória na cena do discurso. In: INDURSKY, F; MITTMANN, S; FERREIRA, M. C. L. (Orgs.). Memória e história na/da análise do discurso. Campinas, SP: Mercado das Letras, 2011, p.67-89.

LEVÍN, F. Humor gráfico - Manual de uso para la historia. $1^{\text {a }}$ ed. Argentina: Ediciones UNGS, 2015.

MARTIGNONE, H. \& PRUNES, M. Historietas a diário - Las tiras cómicas argentinas de Mafalda a nuestros dias. Buenos Aires: Libraria, 2010.

MARTINS, L. B. Memória e resistência: um estudo sobre o pré-construído e o discurso transverso através da ironia em Mafalda. (Doutorado em Letras) - Universidade Federal de Pelotas, Pelotas, 2020.

ORLANDI, E. Prefácio. In: ORLANDI, Eni.(Org.). Discurso Fundador. Campinas: Pontes, p. 7- 9, 1993a.

ORLANDI, E. Vão surgindo sentidos. In: ORLANDI, Eni.(Org.). Discurso Fundador. Campinas: Pontes, p. 11-25, 1993 b.

ORLANDI, E. Texto e Discurso. Organon, vol. 9, n. 23. 1995. http://seer.ufrgs.br/index.php/organon/ article/view/29365/18055

PÊCHEUX, Ml. O discurso - estrutura ou acontecimento. [trad.] Eni Orlandi. Campinas. SP: Pontes Editores, 2008.

PÊCHEUX, M. Semântica e discurso: uma crítica à afirmação do óbvio. Campinas. SP: Editora Unicamp, 2009. 
PÊCHEUX, M. Papel da memória. In: ACHARD, Pierre et al. Papel da Memória. [trad.] José Horta Nunes. Campinas. SP: Pontes Editores, 2010, pp. 49-56.

SIETE DIAS ILUSTRADOS. Revista, Año 3, No 109, 08 a 14-06-1969.

ROMERO, L. A. História contemporânea da Argentina. [Trad.] Edmundo Barreiros. Rio de Janeiro: Jorge Zahar Editora, 2006.

ŽIŽEK, S. Como Marx inventou o sintoma?. In: ŽIŽEK, Slajov (org). Um mapa da Ideologia. Rio de Janeiro: Contraponto, 1996b, pp. 297-331. 